Discussion Paper No. 637

\title{
RECENT COMPETITION IN
}

THE JAPANESE LIFE INSURANCE INDUSTRY

\author{
Toshiyuki Souma \\ and \\ Yoshiro Tsutsui
}

June 2005

The Institute of Social and Economic Research Osaka University

6-1 Mihogaoka, Ibaraki, Osaka 567-0047, Japan 


\title{
Recent Competition in the Japanese Life Insurance Industry*
}

\author{
Toshiyuki Souma \\ (Kyoto Gakuen University) \\ Yoshiro Tsutsui ${ }^{\dagger}$ \\ (Osaka University)
}

suggested running head: Recent Competition in the Japanese Life Insurance Industry

\begin{abstract}
This paper examines a change in the level of competition in the Japanese life insurance industry over the last 17 years. We estimate the first order condition for profit-maximizing insurance oligopolies to obtain the degree of non-competition and collusion. Estimation results suggest that: 1) not only stock companies, but also mutual companies maximize their own profits rather than pay out dividends to policyholders; 2) competition has become stronger since 1995; 3) revision of Insurance Industry Law and failures of insurance companies promoted the competition; and 4) the competition in the recent years is still more lax than the pre-war period.
\end{abstract}

JEL Classification Number: G22, L13, L21

Keywords: Life insurance, Degree of competition, Collusion, Japan

\footnotetext{
*An earlier version of this paper was presented at the Monetary Economics Workshop (MEW) and the Annual Meeting of the Japan Economic Society. The authors are grateful to Charles Yuji Horioka, Yasuhiko Tanigawa, Shinsuke Ikeda, Hirofumi Uchida, Takashi Kaneko, Takao Ohkawa, Tomio Iguchi, and Andrew Coors for their comments.

${ }^{\dagger}$ Corresponding author: Yoshiro Tsutsui, Institute of Social and Economic Research, Osaka University, 6-1, Mihogaoka, Ibaraki, 567-0047 Japan, Phone: +81-6-6879-8560, Fax: +81-6-6878-2766, e-mail: tsutsui@econ.osaka-u.ac.jp
} 


\section{Introduction}

The purpose of this paper is to examine whether or not the Japanese life insurance industry has become more competitive in the last 17 years. The financial liberalization introduced in the 1970s has not resulted in increased competition in the traditional banking, securities, and insurance industries (see Ikeo, 1995; Horiuchi, 1999). Liberalization in the insurance industry in particular is lagging behind that of the other financial industries. The level of competition and the economic efficiency of the life insurance industry have thus been considered low. ${ }^{1}$

In 1996, a new Insurance Industry Law was enacted. This resulted in the formation of 11 non-life insurance companies' subsidiaries, which then began business in the life insurance industry. The number of life insurance companies immediately jumped to 41 . In November of the same year, Prime Minister Hashimoto declared the commencement of the Financial Big Bang, and in June 1997 the Insurance Council submitted a report that outlined the anticipated schedule of liberalization for the following four years. Although there is debate as to whether the tempo of the scheduled liberalization was quick enough, such a movement toward liberalization unambiguously suggests that competition in the life insurance industry is improving. This paper attempts to confirm this suggestion.

A huge literature considers the efficiency, productivity, and the economies of scale and of scope in the life insurance industry. ${ }^{2}$ These studies, however, mainly focus on US firms. Few analyses are known regarding Japanese life insurance firms. Tsutsui et al. (1992) and Kitasaka (1996) analyzed scale and scope economies in the Japanese life insurance industry for 20 incumbent firms. Fukuyama (1997) considered the efficiency and productivity growth in the Japanese life insurance industry during the period 1988-1993. McKenzie (2002) estimated the

\footnotetext{
${ }^{1}$ Chuma et al. (1993) examined the technical efficiency of Japanese life insurance companies. They reported that efficiency differs substantially between insurance companies and that it does not depend on the form of the company, i.e., whether it is a mutual or stock company.

${ }^{2}$ Cummins and Weiss (2000) surveyed papers on these topics focusing on the studies using modern frontier efficiency methodologies in both the life and property-liability insurance industries.
} 
cost function, taking into account ownership types.

With regard to the competitiveness of the Japanese life insurance industry, Tsutsui (1990) examined the change in competition in the industry from the end of the Second World War until 1986, using the industrial organization concepts of 'market structure' and 'market performance'. He concluded that the change in market structure and performance since 1980 suggested an increase in competition. When considering that he found signs of liberalization in the data available up until 1986, we may discover that there are more pronounced changes in the level of competition to be revealed in a more recent sample.

This paper takes a more theoretical approach than that of Tsutsui (1990) and directly estimates the degree of competition. Utilizing the regression equations with panel data from 1986 to 2002 , we clearly establish that there has been a change in the degree of competition during that period. One merit of the estimation method used for this paper is that by using panel data, the estimates of the degree of competition are given for each year. ${ }^{3}$ This enables us to investigate the short-term changes in the degree of competition. ${ }^{4}$ The method proposed by Bresnahan (1982) and Lau (1982) only reveals the average degree of competition for a long period because it uses aggregated time series data.

The rest of the paper is organized as follows. In the next section, the recent status of the Japanese life insurance industry is summarized. In section 3, we derive regression equations to clarify the behavior of mutual and stock companies, and to estimate the degree of competition. Section 4 is devoted to a presentation of the estimation results. Firstly, we show the conclusions derived for the purpose of insurance companies. Secondly, we present the indicated levels of non-competition and collusion. Thirdly, the causes for change in these

\footnotetext{
${ }^{3}$ Angelini and Cetorelli (1999) analyzed 1983-97 panel data for Italian banks to estimate the Lerner index.

${ }^{4}$ The method of Panzar and Rosse (1987) enables us to estimate the degree of competition for each year. However, it requires data on input prices for each insurance firm, which are not available to us.
} 
competitive indexes are examined. Fourthly, the recent degree of competition is compared with that which existed in the pre-war period. Section 5 summarizes our conclusions.

\section{The Japanese Life Insurance Industry from 1986 to 2002}

2.1 The life insurance business under the Bubble Economy and the Heisei Depression The period from 1986 to 2002, which we analyze in this paper, consists of the bubble period and the long stagnation. The purpose of the analysis is to evaluate to what extent liberalization proceeded in these 17 years and how the non-competitive situation, which was dominant throughout the post-war period, has changed. We need to be careful that the dramatic movements in Japanese business conditions over these 17 years do not in fact conceal a long-term structural change, if such exists.

The Japanese economy enjoyed a boom, the so-called 'Bubble Economy', in the late 1980s. However, after the stock price bubble burst in 1990 and the land price bubble did likewise in 1991, the Japanese economy fell into a long period of stagnation called 'the Heisei Depression'. In Figure 1, we show the GDP growth rate and the growth rate of the value of policies in force over the whole life insurance industry. The GDP growth rate has been close to zero since 1992. While it rose temporarily in 1995 and 1996, it fell to a negative figure in 1998, and except for 2000 remained negative. Figure 1 shows that the contrast between the boom in the late 1980s and the depression in the $1990 \mathrm{~s}$ is even more pronounced for the life insurance industry. Specifically, whilst the annual growth rate of the value of policies in force was over $10 \%$ in the late 1980s, it declined and reached $-10 \%$ in 1997 and was negative in consecutive years thereafter except for 2001.

Figure 2 shows the change in the current profit rate as the current profit/asset ratio of the corporate sector for all industries and of the life insurance industry for the same period. Whereas the profit rate of the whole industrial sector declined from the 1980 s to the 1990 s, the 
decline of that rate within the life insurance industry was much larger, as that sector deteriorated more than the average for the whole of the sector. The profit rate of the life insurance business was less than $1 \%$ after 1993, whereas that for the whole of industry was greater than $2 \%$.

It is not easy to discover the reasons for this deterioration in the life insurance sector during the 1990s. There is no doubt, however, that the long-term contracts of companies were one cause. Life insurance contracts imply the collection of a premium and payments of claims over a couple of decades, however revenues were not necessarily invested in equivalent long-term assets. Insurance companies thus assumed interest rate variation risks. Such risks were realized in the depression following an unanticipated fall in interest rates when the average for a loan fell from $7.6 \%$ in 1991 to $1.9 \%$ in 2001 .

In Figure 3, the change in yield of assets and the assumed interest rate are shown. The assumed interest rate is the expected return on the assets of the company considered in setting the insurance premium rate. To maintain solvency, the assumed interest is set at a lower level than the premium rate, and the ex-post gain is distributed to policyholders as dividends. In Figure 3, data on the yield of assets are taken from Insurance: issue of life insurance statistics, and data on assumed interest rates are taken from Toyo Keizai Weekly: special issue of life insurance. The assumed interest rate is not a new one, but the average such rate for outstanding contracts that have been available since 1992. Yields of assets have been declining since 1987, falling remarkably after the burst of the bubble. Although the assumed interest rate has also been lowered, the back spread ran to $1.57 \%$ in 1993 and was not dissolved in 2002, because the new assumed interest rate in the bubble period was over $6 \%$.

Reflecting these severe business conditions, several insurance companies, including medium-sized ones such as Nissan, Toho, Daihyaku, Taisho, Chiyoda, Kyoei, and Tokyo Life, went bankrupt in the 1997-2000 fiscal years. 


\subsection{New entry and exit}

The original Insurance Industry Law was established in 1939 and remained intact throughout the post-war period. This enactment was the final step in the transition to a system in which premium rates, dividend rates, and solicitations were regulated. The entry of new firms was strictly regulated following the Second World War, leading to the maintenance of the so-called '20 firms system'. Indeed, no new entry was allowed until December 1975, when Seibu-All State obtained a business license (see Iguchi, 1996). The revision of the Law in 1996 was aimed at keeping pace with an expected transition from the regulated system to a liberalized one.

In the post-war period, financial institutions, banking, securities, and insurance companies, have been segregated from each other. Although in 1993 banks and securities companies were allowed to enter each other's domain by creating subsidiaries, the insurance sector has been kept isolated from the other industries. Deposit interest rates were thoroughly deregulated in 1993 and 1994, and the trade commissions for stocks trading were deregulated in 1998 and 1999. However, the rates of non-life insurances were not deregulated until 2001, and the premium and dividend rates of the life insurance industry still seem to be under the control of the authorities. Essentially, the insurance industry has been left behind by the financial liberalization of the 1980s and 1990s, so that it has remained uncompetitive.

The most remarkable change in the life insurance industry was brought about by the revision of the Insurance Industry Law. The new law permitted mutual entry between life and non-life companies through the establishment of subsidiaries. ${ }^{5}$ Thereafter, a series of failures and mergers of small and medium-sized firms occurred.

The failure of Nissan Life Insurance in April 1997 collapsed the myth that life insurance

\footnotetext{
${ }^{5}$ Life and non-life insurance companies were permitted to enter the third sector of insurance, which is represented by medical and personal accident insurance, from July 2001.
} 
companies never go bankrupt. This failure may also have indicated the end of the so-called ‘convoy administration system' and may have disciplined life insurance firms. On the other hand, this failure triggered the passage of many bills treating insolvency cases in such companies. For example, in order to protect the policyholders of failed companies, the Life Insurance Policyholders Protection Corporation was formed in December 1998. Thereafter, a bill for a prompt corrective action was promulgated in December 1998 and enforced in April 1999. The establishment of this act caused each of the life insurance companies on the verge of insolvency to form a capital alliance with, and become a subsidiary of, a foreign-based company. ${ }^{6}$

In spite of these endeavors, the five small and medium-sized life insurance companies, Daihyaku, Taisyo, Chiyoda, Kyoei, and Tokyo, collapsed in the 2000 fiscal year. The merger of parent non-life insurance companies led to the merger of their life subsidiaries. ${ }^{7}$

In summary, between 1975 and 2002, more than 20 new firms entered the market. For the same period, seven firms exited. These changes resulted in an increase in the number of life insurance companies from 1975 to 1999 , whereas the number decreased from 1999 to 2002 (see Figure 4). In view of these new entrants, a logical question is: Does this change in the number of firms reflect a change in competition in the life insurance industry?

According to the 'market structure-performance hypothesis', if the market concentration decreases as the result of a new entry, the degree of competition should increase. Therefore, let us investigate how the market concentration has changed in the 17-year period. We use the Herfindahl index, taking the total assets as a proxy for firm size. The results are shown in

\footnotetext{
${ }^{6}$ For example, Toho Mutual Life and Daihyaku Mutual Life formed a capital alliance respectively with GE Capital and Manulife Financial of Canada to establish their joint venture. Both companies, however, failed after about a year. Heiwa Life and Nippon Dantai Life become a subsidiary of Aetna and Axa groups in March 2000, respectively.

${ }_{7}^{7}$ For example, in April 2001, Nippon Fire Partner Life and Koa Life merged into NIPPONKOA Life, and Chiyodakasai EBISU Life and Dai-Tokyo Happy Life merged into Aioi Life. Mitsui Mirai Life and Sumitomo Yu-Yu Life merged into Mitsui Sumitomo Kaijo Life in October 2001.
} 
Figure 5. The index decreases from 1986 until 1991, but only slightly. In 1950, the index was 0.1, well below the recent level. Unexpectedly, the Herfindahl index increases for the years after 1996, although extensive new entry occurred at that time. There is thus no evidence that the market concentration decreased substantially in this period.

Whilst the large number of new entrants in 1996 suggests an improvement in competition, the increase in the Herfindahl index after 1996 suggests that, if we rely upon the standard 'market structure-performance hypothesis', the degree of competition decreased. The 'efficiency structure hypothesis' proposed by Demsetz (1973), however, contrarily predicts that the increase in the Herfindahl index is caused by the enhanced competition. We will examine which scenario is really the case by conducting a regression analysis in section 4.3.

\section{The Model}

\subsection{The basic model}

In this section, we derive a model to estimate the degree of competition. ${ }^{8}$ First, let us introduce the variables used in this paper. $q_{i, t}$ is the value of the policies in force, $Q_{t} \equiv \sum_{i=1}^{N} q_{i, t}, I_{i, t}$ is premium income, $Z_{i, t}$ represents claims paid, $D_{i, t}$ represent dividends paid, $A_{i, t}$ is outstanding assets, $r_{i, t}$ represents yields of assets, and $C_{i, t}$ is operating costs. Subscripts $i$ and $t$ represent firm $i$ and period $t$. Then, the profits $\pi_{i, t}$ of firm $i$ at period $t$ are:

$$
\pi_{i, t}=P_{t}\left(Q_{t}\right) q_{i, t}-C_{i, t}\left(q_{i, t}\right)+r_{i, t} A_{i, t}-\Delta R S V_{i, t}
$$

where $P_{t}\left(Q_{t}\right)$ is the inverse demand function for life insurance, $C_{i, t}\left(q_{i, t}\right)$ is the cost function of firm $i$, and $\triangle R S V_{i, t}$ stands for the change in reserve of firm $i$. Here we assume that

\footnotetext{
${ }^{8}$ For a survey of empirical studies on the degree of competition, see Martin (1993) and Bresnahan (1989).
} 
dividends and the mean of claims to be paid are known to policyholders, so that they regard the net premium as the price of a policy. ${ }^{9}$ Subtracting claims paid at the definition of the price of an insurance policy implies that, with this price, the policyholders buy a reduction of the risk of future income variation by their death.

The stock insurance company $i$ chooses $q_{i, t}$ to maximize the profits, given $A_{i, t}, r_{i, t}$, and $\Delta R S V_{i, t} \cdot{ }^{10}$ From the first order condition of the profit maximization, we obtain:

$$
R_{i, t}=M C_{i, t} q_{i, t}+\frac{\mu_{t}}{\eta_{t}} R_{i, t} M S_{i, t}
$$

where $M C_{i, t} \equiv \frac{\partial C_{i, t}}{\partial q_{i, t}}$ is the marginal cost, $\eta_{t} \equiv-\frac{P_{t}}{Q_{t}} \frac{d Q_{t}}{d P_{t}}$ is the price elasticity, $M S_{i, t} \equiv \frac{q_{i, t}}{Q_{t}}$

is the market share of firm and $R_{i, t} \equiv P_{t} q_{i, t}=I_{i, t}-Z_{i, t}-D_{i, t} \cdot \mu_{i, t} \equiv \frac{\partial Q_{t}}{\partial q_{i, t}}$ is assumed to be common for all the firms and is denoted as $\mu_{t}$ in order to capture the industry average degree of competition. ${ }^{11}$

We estimate (2) together with the cost function because marginal cost, $M C$, is not observable. We assume a translog cost function:

$$
\begin{aligned}
\ln C_{i, t}= & b_{0, \mathrm{t}}+b_{0, \mathrm{i}}+b_{1, \mathrm{i}} \overline{\ln q_{i, t}}+b_{2}\left(\overline{\ln q_{i, t}}\right)^{2}+b_{3} \overline{\ln w_{t}}+b_{4} \overline{\ln p_{t}}+b_{5}\left(\overline{\ln w_{t}}\right)^{2}+b_{6}\left(\overline{\ln p_{t}}\right)^{2} \\
& +a_{3} G_{i, t}+a_{4} L_{i, t},
\end{aligned}
$$

where $w$ is the wage rate of the finance and insurance industries and $p$ is the deflator of fixed capital formation. These data are not available for each firm, so we use the data which vary only over time. $\overline{\ln q}, \overline{\ln w}$, and $\overline{\ln p}$ are deviations from their means. ${ }^{12}$ We allow for

\footnotetext{
${ }^{9}$ In reality, dividends and claims will be paid in future periods. In our one-period analysis, this aspect is disregarded.

${ }^{10}$ We assume that profits gained at period $t$ are added into assets and are invested at period $t+1$.

${ }^{11}$ See Bresnahan (1989) for this point.

${ }^{12}$ Using deviations from the means in the translog function is a convention to avoid possible multi-colinearity.
} 
time-variant intercepts $b_{o, t}$, firm-specific intercepts $b_{o, i}$ and firm-specific slopes $b_{1, i}$. The ratio of group insurance $G_{i, t}$ and the ratio of saving insurance $L_{i, t}$ are added to the cost function to eliminate the effect of the composition of various kinds of policies. The expected signs of $a_{3}$ and $a_{4}$ are negative and positive, respectively (see Tsutsui et al., 1992).

Substituting the definition of marginal cost, equation (2) now becomes:

$$
R_{i, t}=b_{1, i} C_{i, t}+2 b_{2} \overline{\ln q_{i, t}} C_{i, t}+\frac{\mu_{t}}{\eta_{t}} M S_{i, t} R_{i, t}+a_{1} G_{i, t}+a_{2} L_{i, t}
$$

Here, $G_{i, t}$ and $L_{i, t}$ are added to the first order condition to eliminate the effect of the composition of various kinds of policies. The signs of $a_{1}$ and $a_{2}$ are not known a priori. ${ }^{13}$ We estimate equations (3) and (4) simultaneously, putting the restriction on the parameters over the equations.

We obtain the estimate of $\mu_{t} / \eta_{t}$, but $\mu_{t}$ cannot be identified. Thus, we evaluate the possible change in $\mu_{t}$, assuming that $\eta_{t}$ is constant over the estimation period. Multiplying $\mu_{t}$ with market share, we get the degree of non-competition $\lambda_{t}$ (Bresnahan, 1982). $\lambda_{t}=0$ corresponds to perfect competition and $\lambda_{t}=1$ to a monopoly. In Cournot competition, when the number of firms is $n, \lambda_{t}=1 / n$.

\subsection{The degree of collusion}

In order to distinguish $\mu_{t}$ from $\eta_{t}$, we conduct another analysis, putting a restriction on the conjectural variations (Clarke and Davies, 1982; Alley, 1993). Specifically, we assume that when firm $i$ increases its production by a certain rate, the other firms $j \neq i$ increase $\alpha$-times $\left(0<\alpha_{t}<1\right)$ of that rate. Thus, for all $i$ and for all $j \neq i$ :

\footnotetext{
${ }^{13}$ An increase in savings life insurance results in an increase in premium income. However, it also leads to an increase in the amount of the policy paid, so that the sign of $a_{2}$ is not determined.
} 


$$
\frac{\partial q_{j, t}}{\partial q_{i, t}}=\alpha_{t} \frac{q_{j, t}}{q_{i, t}} .
$$

If $\alpha_{t}$ equals unity, (5) means that firm $i$ predicts that other firms will respond to an increase of firm $i$ 's production so as to keep the share of every firm unchanged. Alternatively, if $\alpha_{t}$ equals zero, it means that firm $i$ predicts that other firms will not respond at all to its increase in production. This model corresponds to a cooperative game, in which $\alpha_{t}$ represents the degree of collusion. The former case is interpreted as perfect collusion and the latter corresponds to non-cooperative Cournot competition.

The concept of conjectural variation is popular in both applied theoretic and empirical industrial organization. Theorists of industrial organization, however, take a dim view of its ad hoc assumptions about the conduct of firms, its lack of a game-theoretical foundation, and the forcing of dynamics into an essentially static model in which the strategy space and the time horizon of the underlying game are only loosely defined (Fellner, 1949; Friedman, 1983, p.110; Daughety, 1985; Makowski, 1987; and Tirole, 1989, pp. 244-245). These shortcomings are often perceived as the cost that the modeler must pay for realism without compromising simplicity and tractability. However, it is fortunate that Dockner (1992), Cabral (1995), and Pfaffermayr (1999) showed that the concept of conjectural variation can be supported by a consistent theoretical foundation if it is considered a reduced form of a dynamic game. ${ }^{14}$ Their findings can be used to justify a static conjectural variations analysis for both modeling dynamic interactions and estimating the degree of oligopoly power. From the same viewpoint,

\footnotetext{
${ }^{14}$ Using an infinite horizon adjustment cost model, Dockner (1992) demonstrated that any steady state closed-loop (subgame-perfect) equilibrium coincides with a static conjectural variation equilibrium with nonzero conjectures. Cabral (1995) proved that in linear oligopolies, and for an open set of values of the discount factor, there exists an exact correspondence between the conjectural variation solution and the solution of a quantity-setting repeated game with minimax punishments during $T$ periods. Pfaffermayr (1999) followed an idea put forward by Cabral (1995) and demonstrated that the conjectural variation model can be interpreted as the joint-profit-maximizing steady-state reduced form of a price-setting supergame in a differentiated product market under optimal punishment strategies.
} 
we believe that the use of the static model is rationalized by considering it as a reduced form of an (unmodeled) dynamic game.

Summing up (5) over all $j \neq i$, we obtain:

$$
\mu_{i, t} M S_{i, t}=\alpha_{t}+\left(1-\alpha_{t}\right) M S_{i, t}
$$

When $\alpha_{t}=0, \mu_{i, t}=1$, corresponding to the case of Cournot competition. Assuming that $\mu_{i, t}$ is constant over $i$, and substituting (6) into (4), we obtain, instead of (4):

$$
R_{i, t}=b_{1, i} C_{i, t}+2 b_{2} \overline{\ln q_{i, t}} C_{i, t}+\frac{\alpha_{t}}{\eta_{t}} R_{i, t}+\frac{1-\alpha_{t}}{\eta_{t}} M S_{i, t} R_{i, t}+a_{5} G_{i, t}+a_{6} L_{i, t}
$$

\subsection{The objective of mutual insurance companies}

Two ownership structures, mutual and stock, coexist in the life insurance industry, since life insurance was started as mutual aid. Thus, the question: 'Which is the better organizational form, a stock or a mutual company?' has been the concern of much research. ${ }^{15}$ For example, Mayers and Smith (1986) examined the relative efficiency of a stock versus a mutual-ownership structure from the perspective of the agency cost approach. Using the data of 30 companies changing from a stock to a mutual structure, they concluded that this change is on average efficiency-enhancing, whereas Spiller (1972) concluded that the mutual company is less efficient.

Mayers et al. (1997) examined the relationship between board structure and organizational forms and found that mutual companies employ a significantly larger fraction of outside directors than do stock companies. These studies, however, mainly focus on US firms. Nevertheless, quite a few consider the Japanese life insurance industry. Notable are Fukuyama (1997) and McKenzie (2002), which compare the efficiency of Japanese firms of both

\footnotetext{
${ }^{15}$ Mayers and Smith (2000) produced a detailed review of the literature relevant to this topic in the insurance industry.
} 
organizational forms. Fukuyama (1997) found that mutuals and stocks had an identical technology and that the major sources of overall technical inefficiency were pure technical inefficiency in the case of mutuals and scale inefficiency in the case of stocks. He concluded that it is not clear which organizational form, mutual or stock, is preferable in the Japanese life insurance industry. McKenzie (2002) reported that the rate of return equation does not differ between mutual and stock companies, whereas the cost function does.

Most of the incumbent life insurance companies in Japan are mutual companies. ${ }^{16}$ Because the legal owners of mutual companies are policyholders, dividends are not costs, but represent the main objective that the companies should pursue. Mutual insurance companies may thus maximize the surplus defined in equation (1) plus dividends. ${ }^{17}$ In this case, assuming that $D_{i, t}$ is proportional to $q_{i, t}$, we obtain:

$$
\widetilde{R}_{i, t}=b_{1, i} C_{i, i}+2 b_{2} \overline{\ln q_{t}} C_{i, t}+\frac{\mu_{t}}{\eta_{t}} M S_{i, t} R_{i, t}+a_{1} G_{i, t}+a_{2} L_{i, t}
$$

where $\widetilde{R}_{i, t} \equiv P_{t} q_{i, t}+D_{i, t}=I_{i, t}-Z_{i, t}$.

Many people question if the mutual insurance companies are really regulated by the policyholders, arguing that the mutual companies act no differently from stock companies (see Komiya, 1994). On the other hand, some insist that mutual companies are less efficient because the supervision by policyholders is weaker than that by stockholders. It therefore remains controversial whether or not mutual life insurance companies operate for the advantage of policyholders, or if they only seek profits. We will investigate which situation is the closer to reality by comparing equations (4) and (8).

\footnotetext{
${ }^{16}$ Out of the 20 firms existing in 1997, 16 were mutual companies. In recent years, however, it has been argued that the stock company is a more flexible style of insurance company, and consequently, the mutual companies are examining conversion to stock companies. Daido Life converted to a stock company on April 1, 2002.

${ }^{17}$ Note that the surplus is attributed to policyholders of mutual companies. Here we disregard the fact that policyholders change over time, so that the problem of the transfer of the surplus between policyholders emerges.
} 


\section{The Estimation Results}

Our estimation period is from 1986 to 2002, and the samples are restricted to 'domestic corporations' as defined by the Insurance Industry Law. Data used for the estimation are $I_{i, t}$, $Z_{i, t}, D_{i, t}, q_{i, t}, C_{i, t}, G_{i, t}$, and $L_{i, t}$, which are taken from Statistics of Life Insurance Business in Japan, edited and published by the Insurance Research Institute, together with $w_{t}$ and $p_{t}$, which are taken from the NIKKEI NEEDS Macro data file.

4.1 Do mutual companies maximize profits or dividends?

Firstly, let us examine which equation, (4) or (8), better describes the behavior of mutual insurance companies. Constructing:

$$
\widetilde{R}_{i, t}=b_{1, i} C_{i, t}+2 b_{2} \overline{\ln q_{t}} C_{i, t}+\frac{\mu_{t}}{\eta_{t}} M S_{i, t} R_{i, t}+a_{1} G_{i, t}+a_{2} L_{i, t}+\beta D_{i, t},
$$

(4) is derived when $\beta=1$, and (8) is derived when $\beta=0$. Therefore, equations (4) and (8) constitute a non-nested hypothesis.

We apply the double log likelihood ratio test, in which we construct a general specification, i.e., (9), which includes the two equations as nested hypotheses. Then, we conduct two likelihood ratio tests, (4) against (9), and (8) against (9), and compare the results. The estimation method used is three-stage least squares. ${ }^{18}$ The test results are presented in Table 1. When mutual companies are taken as samples, the specification that they maximize dividends plus profits is rejected at the $1 \%$ significance level, whilst the hypothesis that they maximize profits is not rejected. The same results are obtained when the stock companies are taken as

\footnotetext{
18 The instrumental variables are $G_{i, t}, L_{i, t},\left(\overline{\ln q_{t-1}}\right)^{2}, d_{i} \overline{\ln q_{t-1}}, d_{t-1} M S_{i, t-1} R_{i, t-1}, \overline{\ln p_{t-1}}, \overline{\ln w_{t-1}},\left(\overline{\ln p_{t-1}}\right)^{2}$, $\left(\overline{\ln w_{t-1}}\right)^{2}, R_{i, t-1}, M S_{i, t-1}, d_{t}, d_{i}, D_{i, t-1}$ and constants. The variables $d_{t}$ and $d_{i}$ are the time and firm dummies, respectively.
} 
samples, as we expected. Thus, we conclude that both mutual and stock companies seek only profits, rather than dividends plus profits. The behavior of these two types of company does not differ, at least with respect to their objectives.

\subsection{The results of the basic analysis}

Given the results of the former subsection, we conduct the following analyses assuming that both mutual and the stock companies maximize their profits. We define the two models that we wish to estimate. The first model, described by equations (3) and (4), shall henceforth be called the estimation of the degree of non-competition. The second model, given by equations (3) and (7), will be called the estimation of the degree of collusion.

The result of the three-stage least squares estimation of the degree of non-competition is shown in Table $2 .{ }^{19}$ The model fits well since the determination coefficient of equation (4) is over 0.99 and that of the translog cost function (3) is 0.90 .

In the estimation of first order condition (4), the coefficients of group insurance and saving insurance $a_{1}$ and $a_{2}$ are significantly positive, implying that companies with more of these insurances tend to earn more revenues. On the other hand, $a_{3}$ and $a_{4}$ are not significant in the cost function, implying that these variables do not affect costs. $b_{2}$, which appears in both (3) and (4), is positive and highly significant and the $b_{1, i}$ are all positive; 28 of the $52 b_{1, i}$ are significant at the $5 \%$ level. However, the coefficients of $\ln w_{t}$ and $\ln p_{t}$ and their squared terms are all insignificant. This is probably because yearly data only are available for these variables. $\mu_{t} / \eta_{t}$ are all highly significant, implying that the market has not been perfectly competitive.

\footnotetext{
19 In the estimation, we use $G_{i, t}, L_{i, t},\left(\overline{\ln q_{t-1}}\right)^{2}, d_{i} \overline{\ln q_{t-1}}, d_{t-1} M S_{i, t-1} R_{i, t-1}, \overline{\ln p_{t-1}}, \overline{\ln w_{t-1}},\left(\overline{\ln p_{t-1}}\right)^{2}$, $\left(\overline{\ln w_{t-1}}\right)^{2}, R_{i, t-1}, M S_{i, t-1}, d_{t}, d_{i}$, and constants as instrumental variables.
} 
The estimates of the degree of non-competition $\lambda_{t} / \eta_{t}$ are depicted in Figure 6 , together with their $95 \%$ confidence interval. This takes on a value between 0.25 and 0.31 during the period from 1986 to 1994 , and then decreases sharply, reaching 0.17 in 1996 . Thereafter, it remains almost constant. We thus conclude that the life insurance industry has become more competitive since 1995. The new Insurance Industry Law was passed in the Diet and promulgated in 1995 . The insurance companies probably started various reforms, including the preparation of the establishment of their subsidiaries in 1995, to prepare for the enforcement of the law in the next year. The results reasonably reflect this fact.

Table 3 presents the estimation results of the degree of collusion. The coefficient of group insurance has a significantly negative sign in this case, whilst that of saving insurance has a positive sign in equation (7). The former is a different result from that in Table 2 , but the sign is not known a priori. Group insurance has a significant negative coefficient in the cost function as expected, whereas that of saving insurance is insignificant. Notably $b_{2}$ is positive and highly significant. Estimates of $b_{1, i}$ are all positive, and 34 of the $46 b_{1, i}$ are significant at the 5\% level. ${ }^{20}$ Input prices are not significant in the cost function.

Estimates of the degree of collusion $\alpha_{t}$ are close to unity and highly significant, implying that the market was close to perfect collusion and Cournot competition is rejected. Estimates of demand elasticity $\eta_{t}$ are also close to unity and decrease over the sample period.

The estimates of the degree of collusion $\alpha_{t}$ are depicted in Figure 7 together with their 95\% confidence interval. $\alpha_{t}$ remains almost at the same level around unity until 1991, and then falls sharply, reaching 0.7 in 2002. The degree of collusion does not reject perfect

\footnotetext{
${ }^{20}$ In this estimation, we assume that six firms that existed for only two years of our sample period have the same firm-specific intercepts $b_{o, i}$ and firm-specific slopes $b_{1, i}$ as each other in order to avoid the problems of the singularities of the data and derivatives.
} 
collusion until 1994, but rejects it thereafter. However, the value of $\alpha_{t}$ suggests that the competition is still lax. Whereas $\alpha_{t}$ rejects 'perfect collusion' at the $5 \%$ significance level after 1995, it is far from Cournot competition.

The result for the degree of collusion is consistent with the results of the degree of non-competition in that the insurance industry became competitive over the whole observation period. However, the patterns are somewhat different. The degree of collusion remained constant until 1991, and then decreased monotonically. On the other hand, the degree of non-competition decreased moderately until 1994, and fell sharply in 1995 and 1996, to become stagnant thereafter.

Which pattern is more reliable? We should notice that the degree of competition assumes constant demand elasticity $\eta_{t}$. If this elasticity varies substantially, the estimates do not represent competitiveness correctly. We obtained the estimates of $\eta_{t}$ from the estimation of collusion. So let us apply the estimates to calculate $\lambda_{t}$. The results are presented in Figure 8 and in the right-hand column of Table 2. Looking at the figure, we notice that it rejects monopoly $\left(\lambda_{t}=1\right)$ as well as Cournot oligopoly $\left(\lambda_{t}=1 / n\right)$ throughout the period. That the Cournot oligopoly is rejected reflects the same outcome as for the degree of collusion. However, the fact that monopoly is rejected might contradict the result that perfect collusion prevailed until 1994. The pattern of the graphs shows that the degree of non-competition was almost constant around 0.35 until 1991, which is consistent with the observed degree of collusion. However, the degree of non-competition is seen to have been stagnant after 1996 . This agrees with Figure 6 and differs from that of the degree of collusion.

We are not sure which pattern is correct a priori. However, considering that various policy measures were taken that related to the failure of insurance companies, the results indicating that competition improved consecutively after 1995, the pattern of collusion, best fit our 
intuition.

\subsection{Causes of the progress in competitiveness}

In this subsection, let us try to find out how the degree of collusion and degree of non-competition depend on the various elements. Here, we consider the effect of deregulation, i.e., the promulgation of the Insurance Law and the change of policy that ended the convoy system and allowed the failure of insurance firms. In addition, we consider the variables representing business condition (composite index) and market concentration (Herfindahl index). The regression equation is

$$
Y_{t}=A_{0}+A_{1} C I X_{t}+A_{2} H I_{t}+A_{3} D I L_{t}+A_{4} D F A I L_{t}+u_{t}, \quad Y=\alpha, \lambda / \eta, \text { or } \lambda
$$

Here, $C I X$ is the composite index, $H I$ is the Herfindahl index, DIL is a dummy variable that represents the revision of the Insurance Industry Law, which takes the value 1 in 1995 and 1996, and 0 otherwise, and DFAIL is a dummy variable that represents the failure of insurance companies, which takes the value 1 in the fiscal years 1997-2000, and 0 otherwise.

If these new policies have a significant effect on competition, $A_{3}$ and $A_{4}$ are negative. We cannot predict the sign of business conditions a priori. The coefficient of the Herfindahl index will be positive if the structure-performance hypothesis applies, and negative if the efficient-structure hypothesis is the case (Demsetz, 1973, Berger, 1995).

The estimation results are presented in Table 4. In the left columns, the results for the degree of collusion are shown. The coefficient of composite index is significantly positive, implying that competition was more lax than when business conditions were better. The coefficient of the Herfindahl index is significantly negative, supporting the efficient-structure hypothesis. Herfindahl index rose after 1995 because the insurance companies became more efficient. $A_{3}$ and $A_{4}$, which represent the effect of policy measures, are negative, implying that 
these changes in policy really promoted competition. ${ }^{21}$

In the middle and right columns, we show the results of $\lambda / \eta$ and $\lambda$, respectively. Here, we calculate $\lambda$ using the value of $\eta$ in the estimation of the degree of collusion. They confirm the results based on $\alpha$ except that the business condition does not affect competition in the case of $\lambda$ and $\lambda / \eta$. Thus, we conclude that the recent deregulation policy, including the revision of the insurance law and the abolition of the convoy administration, made the insurance industry more competitive.

\subsection{Comparison with the pre-war period}

It is said that in the pre-war period, the competition amongst life insurance companies was quite severe (Tsutsui et al., 2004). Premium and dividend rates were not regulated until 1937, nor was sales staff activity (in terms of insurance solicitation) restricted until 1931. Insurance companies tried to mitigate competition by means of different premium-dividend schemes in 1917-1937 (Tsutsui et al., 2000).

It is interesting to investigate, therefore, whether the current degree of competition is as great as that in the pre-war period. We estimated the degree of non-competition and degree of collusion using cross-section data for 1916, 1917, and 1922, when the competition was quite fierce. It was not necessary to include $w_{t}$ and $p_{t}$ because the regression is cross-sectional, and $G_{i, t}$ and $L_{i, t}$ were omitted from our estimations because of the unavailability of data.

In Figure 7, we show the degree of collusion for those years. It is about 0.5 and lower than for recent years, suggesting that the current competition is still weaker than during the pre-war period.

\footnotetext{
${ }^{21}$ Revision of the Insurance Industry Law induced a remarkable increase in the number of firms, so that we estimated eq. (10) replacing DIL with the net change in their number. The coefficient was negative, but the $p$ value was only $15 \%$. We also estimated eq. (10) replacing DFAIL with the asset value of the companies in default. The coefficient was negative, but insignificant.
} 
The degree of non-competition for the pre-war years is shown in Figure 6 . These values are around 0.19 and slightly higher than that for the current years. However, since the degree of non-competition is divided by demand elasticity, and since it is not convincing to assume this elasticity to have been the same for the pre- and post-war periods, we should not directly compare these values. Let us therefore adopt the value of $\eta_{t}$ for the estimation of the degree of collusion and multiply these estimates to get $\lambda_{t}$. The result is shown in Figure $8 . \lambda_{t}$ in 2002 is 0.15 , whilst it is 0.134 in 1916 , suggesting that the current competition is almost at the level that was attained during the pre-war period.

Which result, Figure 7 or Figure 8, is more appropriate with regard to the level of competition? The suggestion that the current competition is as severe as that which occurred in the pre-war period when there were no particular policies that would restrict competition is not very convincing. In this regard, the collusion result appears to be the more reliable.

\section{Conclusions}

In this paper, we have examined the change in the degree of competition existing in the Japanese life insurance industry for the 1986-2002 period. Firstly, we investigated whether Japanese life insurance companies of both stock and mutual structure seek profits or dividends. Then, estimating the first order condition of the profit maximization, together with the cost function, we obtained estimates of the degree of non-competition and collusion. We also sought the causes of progress in competition and compared the competitiveness with that of the pre-war period. The conclusions we obtained from the estimation results are summarized as follows:

1) Both stock and mutual companies seek to maximize profits rather than dividends to policyholders. 
2) The degree of non-competition fell until 1996, and has remained almost unchanged thereafter. It fell particularly sharply in 1995 and 1996, when the new Insurance Industry Law was promulgated and enforced.

3) The estimation of the degree of collusion reveals that competition has improved monotonically since 1992. The degree of collusion does not reject perfect collusion until 1994, but rejects it thereafter.

4) The degree of collusion has improved following policy changes such as the revision of the Insurance Industry Law and the abolition of the convoy system, since which the failure of insurance companies has been admitted. The Herfindahl index has a positive correlation with the degree of competition, as the efficient-structure hypothesis predicts.

5) The degree of collusion in the later years is greater than that for the pre-war period, suggesting that there remains room for more competition.

Let us compare the results of this paper with those available for the competitiveness of the other Japanese financial industries. Uchida and Tsutsui (2005), using an approach similar to the one applied in this paper, considered the Japanese banking industry and estimated the degree of competition from 1974 to 2000 . They found that the market had become more competitive in the 1970s, and judged that the city banks faced perfect competition in the middle of the 1990s. Estimating Panzar-Rosse's H-statistic, Tsutsui and Kamesaka (2005) found that the Japanese securities industry was in monopolistic competition equilibrium in the 1980s and late 1990s and was in monopoly equilibrium in the early 1990s. In view of these findings, life insurance in Japan seems to be a less competitive industry than banking. Competition in banking improved in the late 1970s. Whereas it improved in the life insurance sector during the late 1990s, it did not reach perfect competition. 


\section{References}

Alley, W.A., 1993. Collusion versus efficiency in the Japanese regional banking industry. Economic Studies Quarterly 44, 206--215.

Angelini, P., Cetorelli, N., 1999. Bank competition and regulatory reform: the case of the Italian banking industry. Working Paper Series, Research Department, Federal. Reserve Bank of Chicago, WP 99-32.

Berger, A., 1995. The profit-structure relationship in banking--tests of market-power and efficient-structure hypotheses. Journal of Money, Credit, and Banking 27 (2), 404--431.

Bresnahan, T.F., 1982. The oligopoly solution concept is identified. Economics Letters 10, 87--92.

Bresnahan, T. F., 1989. Empirical studies of industries with market power, in: Schmalensee, R., Willig, R. (Eds.), Handbook of Industrial Organization, Vol. 2. North-Holland, Amsterdam, pp. 1011--1058.

Cabral, L., 1995. Conjectural variations as a reduced form. Economics Letters 49, 397--402.

Chuma, H., Tachibanaki, T., Takada, S., 1993. Seimei hoken gaisha no koritsusei no keisoku (In English: Estimation of the efficiency of life insurance companies), in: Chuma, H., Tachibanaki, T. (Eds.), Seimei Hoken no Keizai Bunseki (In English: Economic Analysis of Life Insurance). Tokyo: Nippon Hyoron Sha, pp. 197--230.

Clarke, R., Davies, S.W., 1982. Market structure and price-cost margins. Economica 49, 277--287.

Cummins, J.D., Weiss, M.A., 2000. Analyzing firm performance in the insurance industry using Frontier Efficiency and Productivity Methods, in: Dionne, Georges (Ed.), Handbook of Insurance. Boston; Dordrecht and London: Kluwer Academic, pp. 767--829.

Daughety, A. F., 1985. Reconsidering Cournot: the Cournot equilibrium is consistent. Rand Journal of Economics 16, 368--379.

Demsetz, H., 1973. Industry structure, market rivalry, and public policy. Journal of Law and Economics $16(1), 1--9$. 
Dockner, E. J., 1992. A dynamic theory of conjectural variation. Journal of Industrial Economics 40, 377--395.

Fellner, W. J., 1949. Competition among the few. New York, NY: Knopf.

Friedman, J. W., 1983. Oligopoly Theory. Cambridge, MA: Cambridge University Press.

Fukuyama, H., 1997. Investigating productive efficiency and productivity changes of Japanese life insurance companies. Pacific-Basin Finance Journal 5, 481--509.

Horiuchi, A., 1999. Nippon Keizai to Kin’yu Kiki (In English: Japanese Economy and Financial Crisis). Tokyo: Iwanami Shoten.

Iguchi, T., 1996. Gendai Hokengyo no Sangyo Soshiki (In English: Industrial Organization of the Contemporary Insurance Industry). Tokyo: NTT Publishing Ltd.

Ikeo, K., 1995. Kin'yu Sangyo eno Keikoku (In English: An Alarm to the Financial Industry). Tokyo: Toyo Keizai Shinpo Sha.

Kitasaka, S., 1996. Seimei hokengyo no kibo to han'i no keizaisei - baburu keizai houkaigo wo taisho tosite (In English: Scale and scope economies of the life insurance industry after Japan’s bubble economy collapsed). Japan Financial Review 21, 61--83.

Komiya, R., 1994. The life insurance company as a business enterprise, in: Imai, K., Komiya, R. (Eds.), Business Enterprise in Japan: Views of Leading Japanese Economists. Cambridge, MA: MIT Press, pp. 365--386.

Lau, L.J., 1982. On identifying the degree of competitiveness from industry price and output data. Economics Letters 10, 93--99.

Makowski, L., 1987. Are 'rational conjectures' rational?. Journal of Industrial Economics 36, $35--47$.

Martin, S., 1993. Advanced Industrial Economics. Oxford: Blackwell.

Mayers, D., Smith, C.W. Jr., 1986. Ownership structure and control: the mutualization of stock life insurance companies. Journal of Financial Economics 16, 73--98.

Mayers, D., Smith, C.W. Jr., 2000. Organizational forms within the insurance industry: theory and evidence, in: Dionne, Georges (Ed.), Handbook of Insurance. Boston: Dordrecht and London: Kluwer Academic, pp. 689--707. 
Mayers, D., Shivdasani, A., Smith, C.W. Jr., 1997. Board composition and corporate control: evidence from the insurance industry. Journal of Business 70, 33--62.

McKenzie, C., 2002. Seimei hoken sogo gaisha no kabushikika nituite (in English: On the conversion of mutual life insurance companies to stock companies), in: Matsuura, K, T. Hayashi (Eds.), Kin’yu Henkaku no Jissho Bunseki (In English: Empirical Analyses of Financial Changes). Tokyo: Nippon Hyoron Sha, pp. 219--240.

Panzar, J.C., Rosse, J.N., 1987. Testing for 'monopoly' equilibrium. Journal of Industrial Economics 35, 443--456.

Pfaffermayr, M., 1999. Conjectural-variation models and supergames with price competition in a differentiated product oligopoly. Journal of Economics 70(3), 309--326.

Spiller, R., 1972. Ownership and performance: stock and mutual life insurance companies. Journal of Risk and Insurance 34, 17--25.

Tirole, J., 1989. The Theory of Industrial Organization. Cambridge, MA: MIT Press.

Tsutsui, Y., 1990. Seimei hokengyo no shijo kozo to seika (In English: Market structure and performance of the life insurance industry). Japan Financial Review 12, $21--40$.

Tsutsui, Y., Kamesaka, A. 2005. Degree of competition in the Japanese securities industry. Journal of Economics and Business, in press.

Tsutsui, Y., Sekiguchi, M., Chano, T., 1992. Seimei hokengyo no kibo to han'i no keizaisei (In English: Scale and scope economies of the life insurance industry). Japan Financial Review 15, 1--15.

Tsutsui, Y., Sekiguchi, M., Chano, T., 2000. The premium-dividend competition in the pre-war Japanese life insurance industry: a game theoretic interpretation. Japanese Economic Review 51 (4), 519--535.

Tsutsui, Y., Sekiguchi, M., Chano, T., 2004. Japanese life insurance industry in the interwar period. Osaka Economic Papers 54 (1), 1--24.

Uchida, H., Tsutsui, Y., 2005. Has competition in the Japanese banking sector improved? Journal of Banking and Finance 29, 419--439. 
Table 1 Results of the Double Log Likelihood Ratio Tests of the Objectives of Mutual and Stock Life Insurance Companies

\begin{tabular}{ccc}
\hline & Mutual companies & Stock companies \\
\hline (4) against (9): p-values & 0.157 & 0.760 \\
(8) against (9): p-values & 0.002 & 0.001 \\
\hline
\end{tabular}

Note: (4) and (8) represent models of the maximization of profits and the maximization of dividends plus profits, respectively. (9) is a general specification that includes (4) and (8) as special cases. 
Table 2 Estimates of the Degree of Non-competition

\begin{tabular}{|c|c|c|c|c|}
\hline Parameter & Estimate & P-value & $\lambda_{t} / \eta_{t}$ & $\lambda_{t}$ \\
\hline$\mu_{1986} / \eta_{1986}$ & 7.507 & {$[.000]$} & 0.313 & 0.339 \\
\hline$\mu_{1987} / \eta_{1987}$ & 7.333 & {$[.000]$} & 0.306 & 0.325 \\
\hline$\mu_{1988} / \eta_{1988}$ & 7.194 & {$[.000]$} & 0.288 & 0.328 \\
\hline$\mu_{1989} / \eta_{1989}$ & 7.200 & {$[.000]$} & 0.288 & 0.338 \\
\hline$\mu_{1990} / \eta_{1990}$ & 7.361 & {$[.000]$} & 0.283 & 0.342 \\
\hline$\mu_{1991} / \eta_{1991}$ & 7.339 & {$[.000]$} & 0.272 & 0.338 \\
\hline$\mu_{1992} / \eta_{1992}$ & 6.922 & {$[.000]$} & 0.256 & 0.287 \\
\hline$\mu_{1993} / \eta_{1993}$ & 6.784 & {$[.000]$} & 0.251 & 0.269 \\
\hline$\mu_{1994} / \eta_{1994}$ & 6.869 & {$[.000]$} & 0.254 & 0.267 \\
\hline$\mu_{1995} / \eta_{1995}$ & 6.657 & {$[.000]$} & 0.230 & 0.224 \\
\hline$\mu_{1996} / \eta_{1996}$ & 6.826 & {$[.000]$} & 0.166 & 0.159 \\
\hline$\mu_{1997} / \eta_{1997}$ & 6.730 & {$[.000]$} & 0.168 & 0.157 \\
\hline$\mu_{1998} / \eta_{1998}$ & 6.846 & {$[.000]$} & 0.171 & 0.155 \\
\hline$\mu_{1999} / \eta_{1999}$ & 6.582 & {$[.000]$} & 0.161 & 0.136 \\
\hline$\mu_{2000} / \eta_{2000}$ & 6.068 & {$[.000]$} & 0.156 & 0.133 \\
\hline$\mu_{2001} / \eta_{2001}$ & 6.215 & {$[.000]$} & 0.164 & 0.133 \\
\hline$\mu_{2002} / \eta_{2002}$ & 6.171 & {$[.000]$} & 0.181 & 0.150 \\
\hline$a_{1}$ & $4.569 \times 10^{4}$ & {$[.025]$} & & \\
\hline$a_{2}$ & $4.796 \times 10^{5}$ & {$[.000]$} & & \\
\hline$a_{3}$ & -0.250 & {$[.885]$} & & \\
\hline$a_{4}$ & 0.068 & {$[.973]$} & & \\
\hline$b_{2}$ & 0.276 & {$[.000]$} & & \\
\hline$b_{3}$ & -165.856 & {$[.678]$} & & \\
\hline$b_{4}$ & -48.206 & {$[.728]$} & & \\
\hline$b_{5}$ & 798.980 & [.676] & & \\
\hline$b_{6}$ & -422.421 & [.709] & & \\
\hline$R^{2}$ for (3) & 0.899 & & & \\
\hline$R^{2}$ for (4) & 0.992 & & & \\
\hline
\end{tabular}

Note: The results of simultaneous estimation of eqs. (3) and (4) are shown. Estimates of $b_{o, t}$, $b_{o, i}$, and $b_{1, i}$ are omitted to save space. Observations are for all existing life insurance firms. $\lambda_{t} / \eta_{t}$ is calculated by multiplying $\mu_{t} / \eta_{t}$ by the number of companies. $\lambda_{t}$ is calculated by multiplying $\lambda_{t} / \eta_{t}$ by $\eta_{t}$ presented in Table 3 . 
Table 3 Estimates of the Degree of Collusion

\begin{tabular}{|c|c|c|c|c|c|}
\hline Parameter & Estimate & P-value & Parameter & Estimate & P-value \\
\hline$\alpha_{1986}$ & 1.022 & {$[.000]$} & $\eta_{1986}$ & 1.084 & {$[.000]$} \\
\hline$\alpha_{1987}$ & 0.998 & {$[.000]$} & $\eta_{1987}$ & 1.064 & {$[.000]$} \\
\hline$\alpha_{1988}$ & 1.082 & {$[.000]$} & $\eta_{1988}$ & 1.139 & {$[.000]$} \\
\hline$\alpha_{1989}$ & 1.110 & {$[.000]$} & $\eta_{1989}$ & 1.174 & {$[.000]$} \\
\hline$\alpha_{1990}$ & 1.121 & {$[.000]$} & $\eta_{1990}$ & 1.209 & {$[.000]$} \\
\hline$\alpha_{1991}$ & 1.144 & {$[.000]$} & $\eta_{1991}$ & 1.242 & {$[.000]$} \\
\hline$\alpha_{1992}$ & 1.032 & {$[.000]$} & $\eta_{1992}$ & 1.119 & {$[.000]$} \\
\hline$\alpha_{1993}$ & 0.982 & {$[.000]$} & $\eta_{1993}$ & 1.069 & {$[.000]$} \\
\hline$\alpha_{1994}$ & 0.956 & {$[.000]$} & $\eta_{1994}$ & 1.048 & {$[.000]$} \\
\hline$\alpha_{1995}$ & 0.880 & {$[.000]$} & $\eta_{1995}$ & 0.975 & {$[.000]$} \\
\hline$\alpha_{1996}$ & 0.844 & {$[.000]$} & $\eta_{1996}$ & 0.955 & {$[.000]$} \\
\hline$\alpha_{1997}$ & 0.830 & {$[.000]$} & $\eta_{1997}$ & 0.936 & {$[.000]$} \\
\hline$\alpha_{1998}$ & 0.787 & {$[.000]$} & $\eta_{1998}$ & 0.903 & {$[.000]$} \\
\hline$\alpha_{1999}$ & 0.737 & {$[.000]$} & $\eta_{1999}$ & 0.849 & {$[.000]$} \\
\hline$\alpha_{2000}$ & 0.752 & {$[.000]$} & $\eta_{2000}$ & 0.858 & {$[.000]$} \\
\hline$\alpha_{2001}$ & 0.703 & {$[.000]$} & $\eta_{2001}$ & 0.811 & {$[.000]$} \\
\hline$\alpha_{2002}$ & 0.708 & {$[.000]$} & $\eta_{2002}$ & 0.824 & {$[.000]$} \\
\hline$a_{3}$ & -0.892 & {$[.000]$} & & & \\
\hline$a_{4}$ & -0.186 & {$[.285]$} & & & \\
\hline$a_{5}$ & $-2.024 \times 10^{4}$ & {$[.000]$} & & & \\
\hline$a_{6}$ & $2.802 \times 10^{4}$ & [.059] & & & \\
\hline$b_{2}$ & 0.052 & {$[.000]$} & & & \\
\hline$b_{3}$ & -27.056 & {$[.300]$} & & & \\
\hline$b_{4}$ & -6.649 & {$[.461]$} & & & \\
\hline$b_{5}$ & 132.894 & {$[.285]$} & & & \\
\hline$b_{6}$ & -58.224 & {$[.425]$} & & & \\
\hline$R^{2}$ for (3) & 0.997 & & & & \\
\hline$R^{2}$ for (7) & 0.999 & & & & \\
\hline
\end{tabular}

Note: The results of simultaneous estimation of eqs. (3) and (7) are shown. Estimates of $b_{o, t}$, $b_{o, i}$, and $b_{1, i}$ are omitted to save space. Observations are for all existing life insurance firms. 


\section{Table 4 Causes of the progress of competition}

\begin{tabular}{ccccccc}
\hline \hline Dependent t variable & \multicolumn{2}{c}{$\alpha$} & \multicolumn{2}{c}{$\lambda / \eta$} & \multicolumn{2}{c}{$\lambda$} \\
\hline \hline Variable & Coefficient & P-value & Coefficient & P-value & Coefficient & P-value \\
\hline \hline Constant & 1.599 & {$[.003]$} & 0.539 & {$[.029]$} & 0.625 & {$[.052]$} \\
CIX & 0.006 & {$[.070]$} & 0.000 & {$[.960]$} & 0.002 & {$[.390]$} \\
$H I$ & -10.204 & {$[.001]$} & -2.519 & {$[.052]$} & -4.484 & {$[.014]$} \\
DIL & -0.180 & {$[.010]$} & -0.076 & {$[.027]$} & -0.116 & {$[.014]$} \\
$D F A I L$ & -0.111 & {$[.042]$} & -0.072 & {$[.014]$} & -0.094 & {$[.015]$} \\
$R^{2}$ & 0.762 & & 0.568 & & 0.656 & \\
\hline \hline
\end{tabular}

Note: We regress the degree of collusion and degree of non-competition over the business condition $(C I X)$, the Herfindahl index $(H I)$, and two year-dummy variables representing deregulations. Number of observations is 17 . 
Figure 1 The GDP Growth Rate and the Growth Rate of the Value of Policies in Force

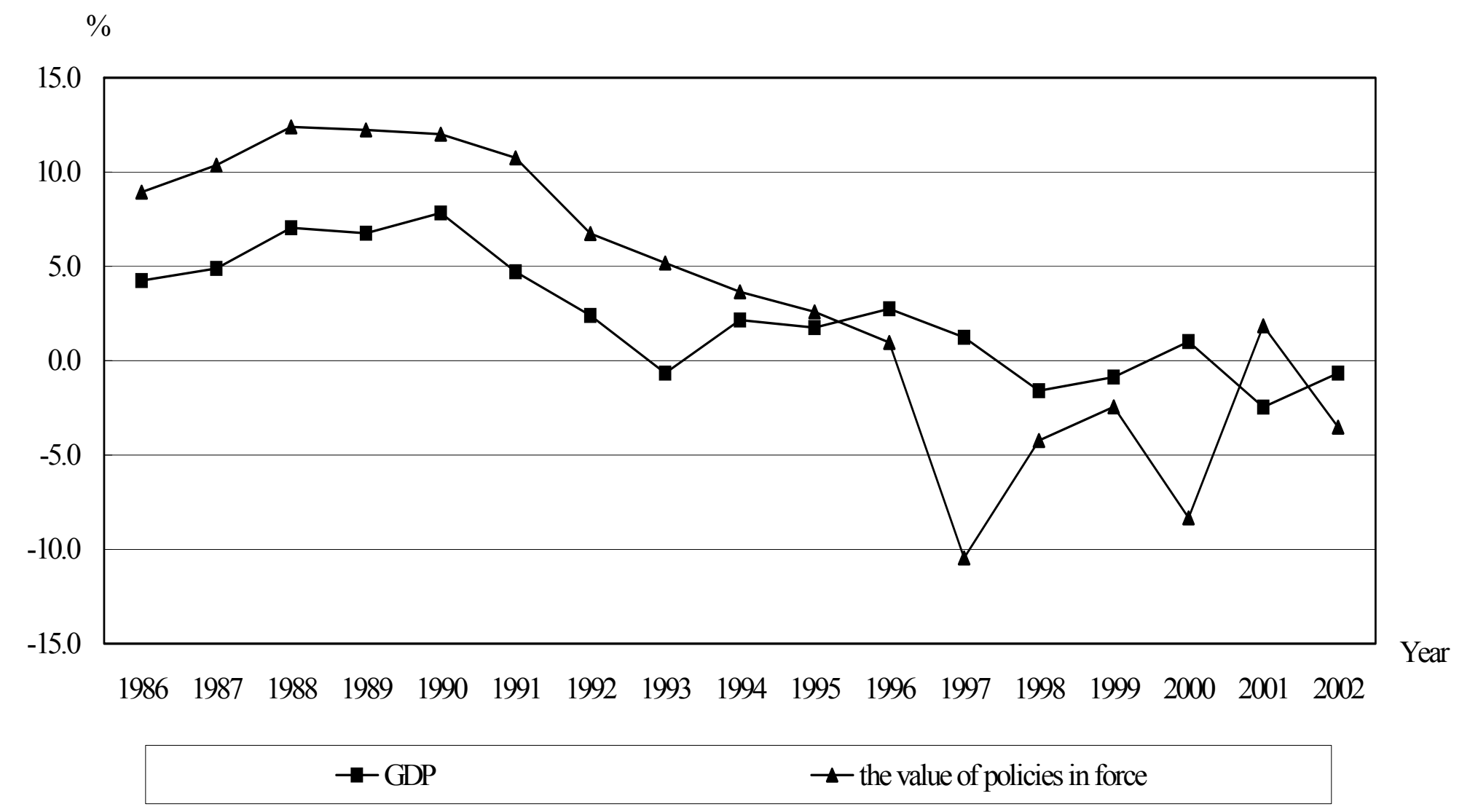

Source: NIKKEI NEEDS Macro data file. 


\section{Figure 2 The Current Profit Rate}

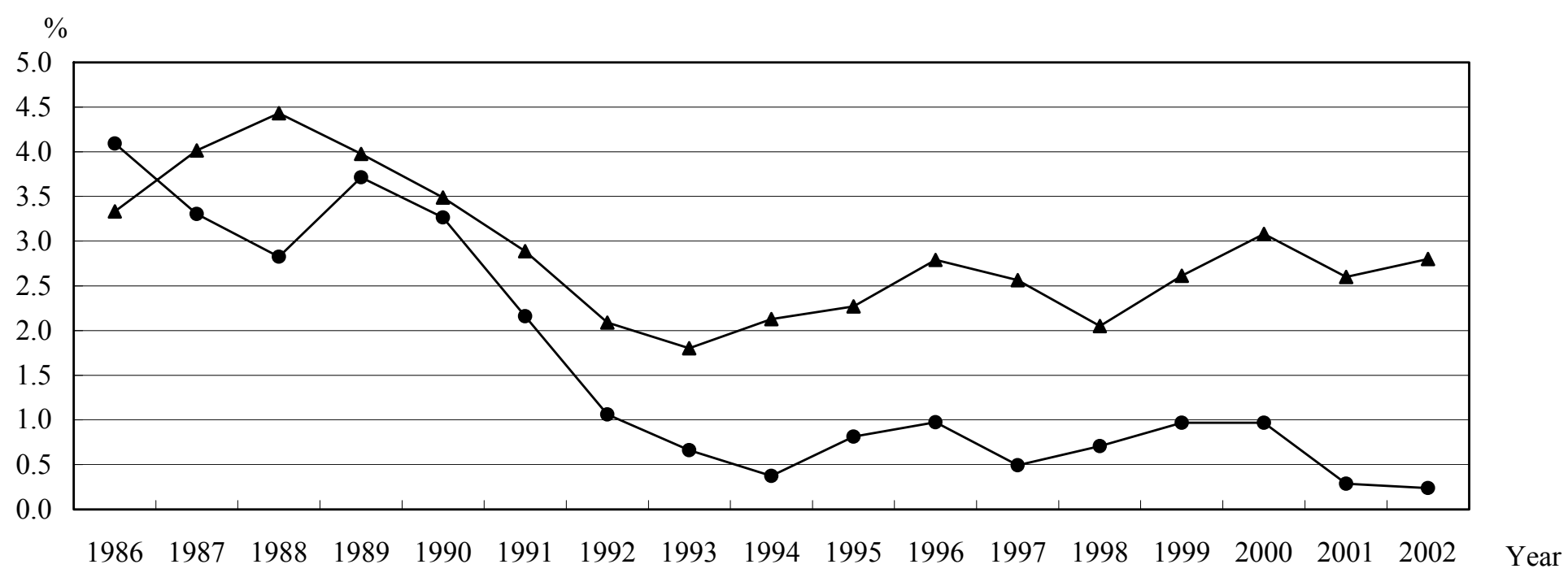

Note: The current profit rate of the life insurance industry and that of the corporate sector of all industries are shown. Current profit rate is the current profit/asset ratio. 
Figure 3 The Yields of Assets and the Assumed Interest Rate

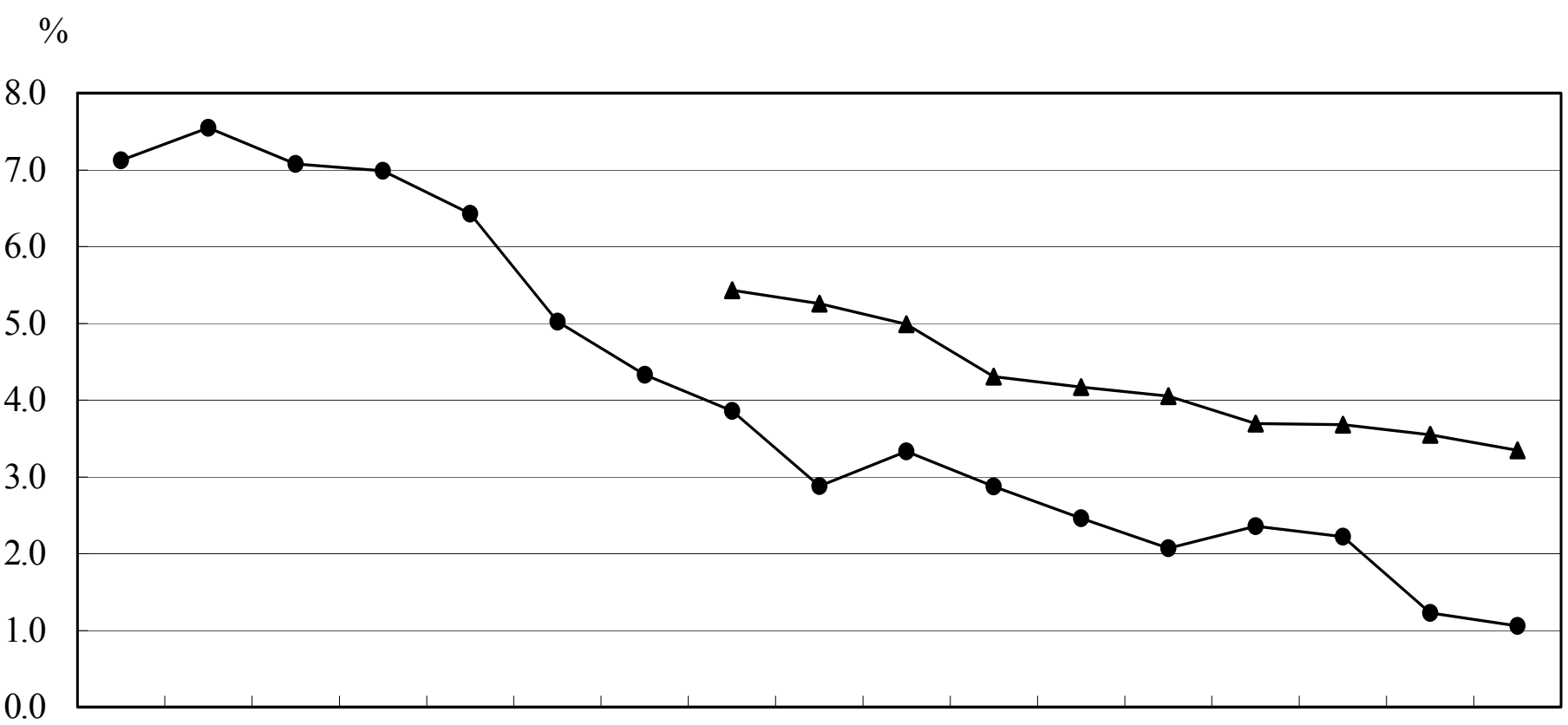

$19861987198819891990199119921993199419951996 \quad 1997 \quad 19981999200020012002 \quad$ Year

$$
\rightarrow \text { assumed interest rate } \quad \rightarrow \text { yields of assets }
$$

Note: The assumed interest rate is the expected rate of return on the assets of the company. The assumed interest rate here is the average for outstanding contracts. Data on the yield of assets are taken from Insurance: issue of life insurance statistics, and data on assumed interest rates is taken from Toyo Keizai Weekly: special issue on life insurance. 
Figure 4 The number of Life Insurance Firms

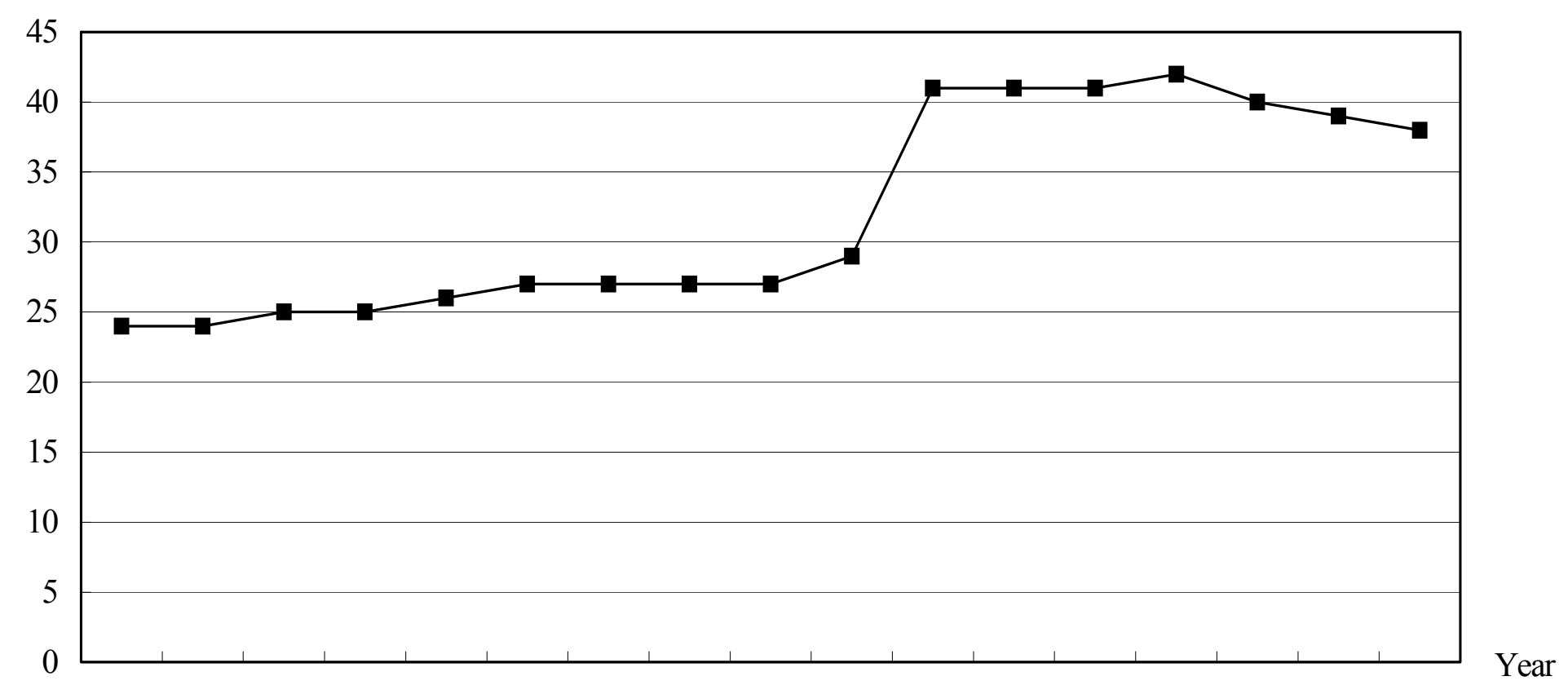

$198619871988198919901991 \quad 19921993 \quad 19941995199619971998 \quad 1999200020012002$

Source: Insurance: issue of life insurance statistics. 


\section{Figure 5 The Herfindahl Index (HI)}

$\mathrm{HI}$

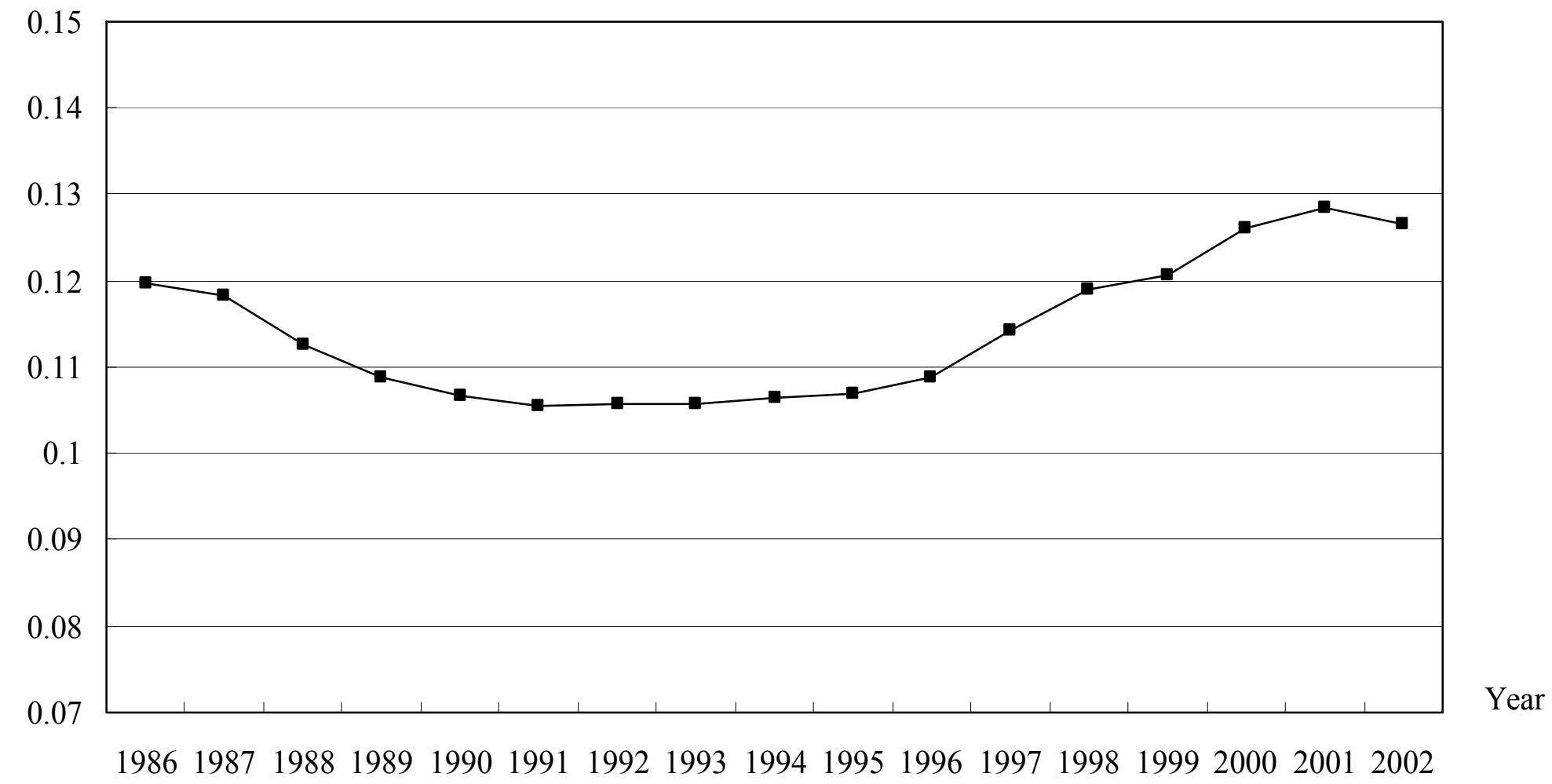

Note: The Herfindahl index, taking the total assets as a proxy for firm size. 
Figure 6 Estimates of the Degree of Non-Competition $\left(\lambda_{t} / \eta_{t}\right)$

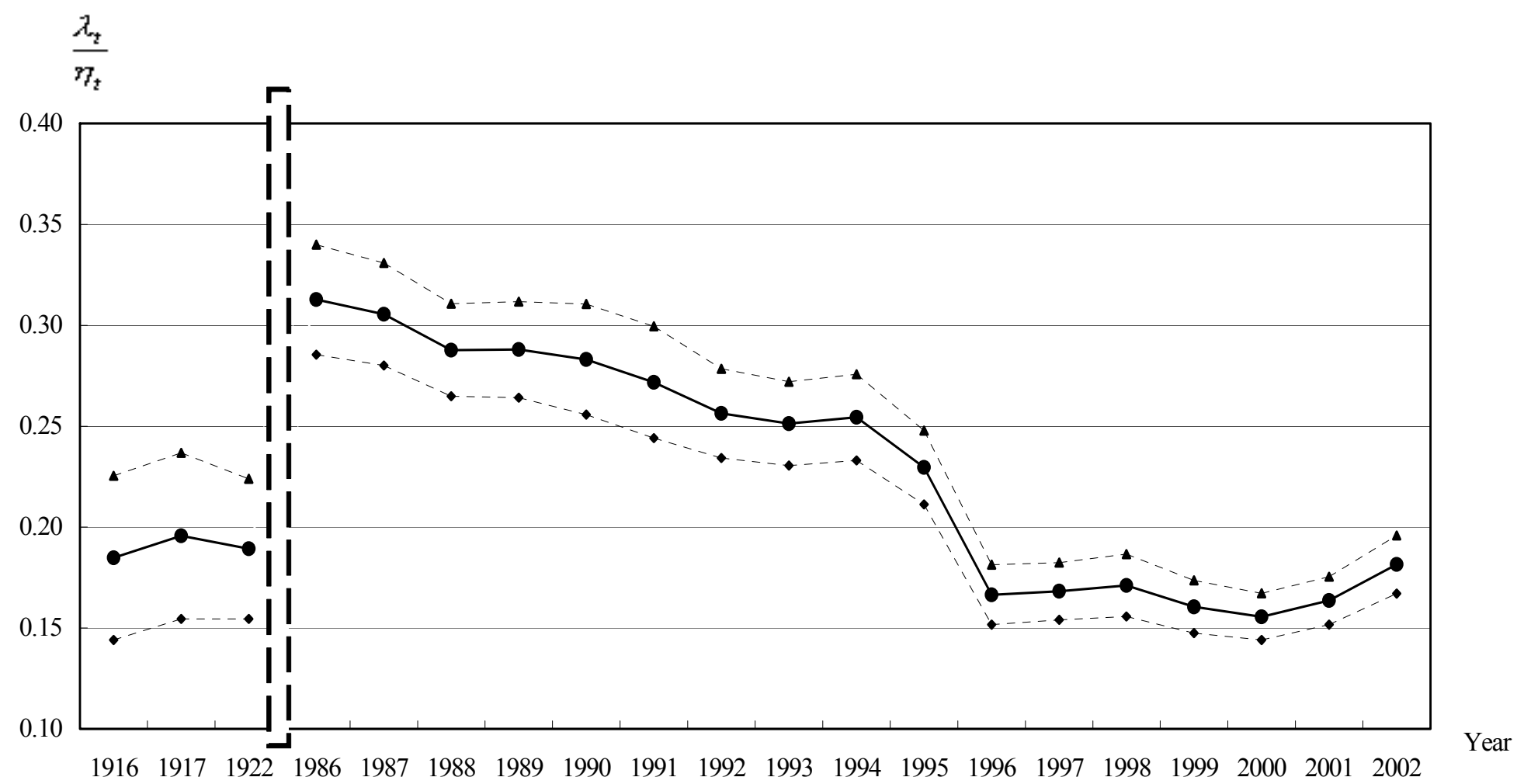

Note: Estimates are based on simultaneous estimation of eqs. (3) and (4). 
Figure 7 Estimates of the Degree of Collusion $\left(\alpha_{t}\right)$

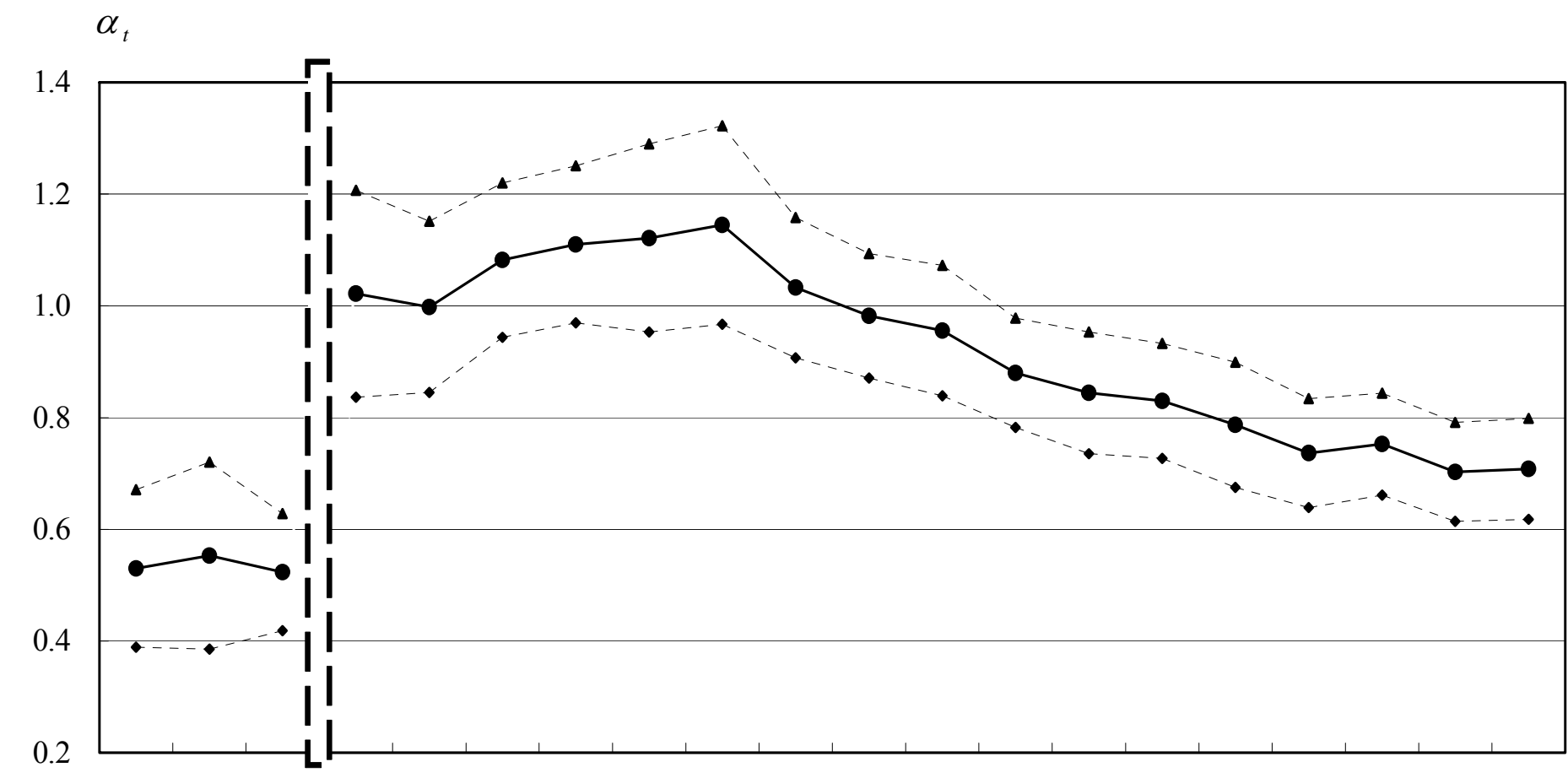

19161917192219861987198819891990199119921993199419951996199719981999200020012002

- - the upper bounds of a 95\% confidence interval - - - the lower bounds of a $95 \%$ confidence interval

Note: Estimates are based on simultaneous estimation of eqs. (3) and (7). 
Figure 8 Estimates of the Degree of Non-Competition $\left(\lambda_{t}\right)$

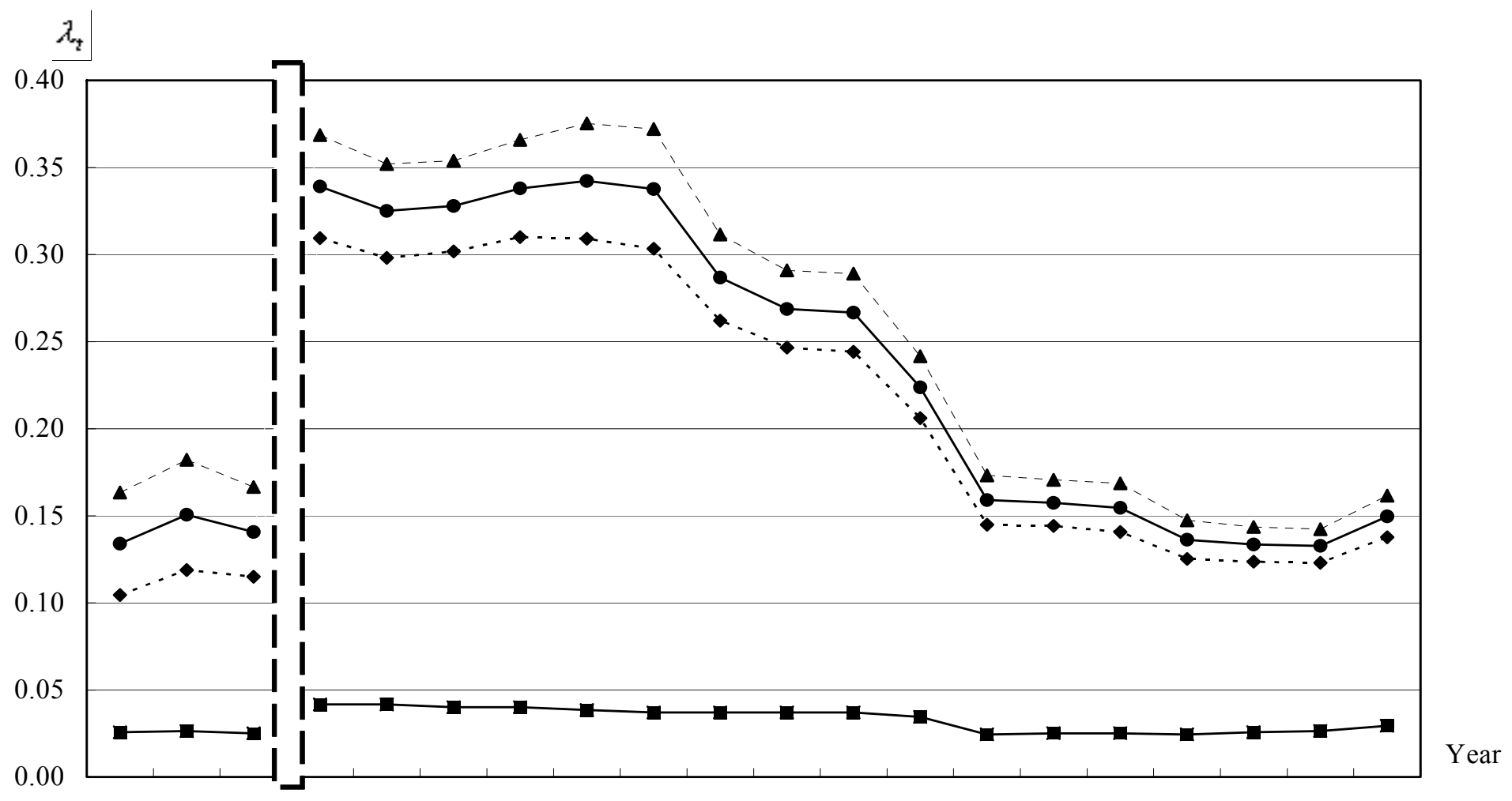

19161917192219861987198819891990199119921993199419951996199719981999200020012002

\- - the upper bounds of a $95 \%$ confidence interval $\cdots \cdots$ the lower bounds of a $95 \%$ confidence interval $\square-1 / n$

Note: $\lambda_{t}$ is calculated by multiplying $\eta_{t}$ taken from the estimation of collusion with the estimates of $\lambda_{t} / \eta_{t}$ shown in Figure 6. Line of $1 / \mathrm{n}$ corresponds to Cournot oligopoly. 